\title{
The Threshold Effect of Sci-tech Finance on Sci-tech Innovation -Empirical Analysis for Provincial Panel Data in China
}

\author{
Weike Zhang ${ }^{1, a}$, Xiaoli Tian ${ }^{2, b}$ and Jiang $\mathrm{Du}^{1, \mathrm{c}, *}$ \\ ${ }^{1}$ School of economics, Sichuan University, Chengdu 610000, China; \\ ${ }^{2}$ Business School, Sichuan University, Chengdu 610000, China. \\ azhangwk123@126.com, ${ }^{\mathrm{b}}$ tianxiaolitxl@126.com, cdujiang_1@163.com
}

Keywords: Sci-tech finance; Sci-tech innovation; Threshold model; Threshold effect

\begin{abstract}
Based on the panel data of 29 provinces (except Tibet and Hainan ) over 2001-2013 period in China, this paper uses threshold panel model to empirical analysis whether they have non-linear and threshold effect between sci-tech finance and sci-tech innovation. The results show that the influence of sci-tech finance on sci-tech innovation in the chinese provinces is not linear, and has obvious threshold effect. Besides, at a relatively low level of economic development, sci-tech finance has a negative impact on the sci-tech innovation. But when economic development to be a certain extent, sci-tech finance would promote sci-tech innovation enhance.
\end{abstract}

\section{Introduction}

Science and technology are the primary productive forces, and Science \&technology innovation (for sci-tech innovation) is the first impetus for structural adjustment, industrial upgrading and economic development. The Eighteenth National Congress and the third Plenary Session of the 18th Central Committee of the CPC clearly pointed out that sci-tech innovation is the strategic support to improve the social productive forces and the comprehensive national strength, and must be placed in the core position of the country's overall development. Sci-tech innovation cannot do without the financial support. Finance is an important lever to promote sci-tech innovation. But in the process of technological development, there are a series of problems to be solved, such as idle resources of science and technology resources, difficulty in achieve optimal allocation, low efficiency of input-output. Therefore, sci-tech innovation must be organically combined with financial innovation, and at the same time they promote each other. Above all, it is an important issue how to use sci-tech finance to promote sci-tech innovation and enhance the core competitiveness of the country.

\section{Theoretical Framework}

The domestic and foreign scholars have studied the correlation between sci-tech finance and sci-tech innovation from different perspectives. Most of the studies focused mainly on the ways how the finance influenced sci-tech innovation. For example, King and Levine (1993) ${ }^{[1]}$ found the causality between finance and economic growth when they took notice of the factor enterprise innovation activities. And they constructed a model of endogenous growth, and thought the financial system can promote innovation, mainly through the ways of evaluating potential projects, raising funds, evaluating the risk of innovative activities and expecting future profits. They believed that the synergy between finance and technology is an important factor in promoting economic growth. Neff $(2012)^{[2]}$ pointed out that finance and sci-tech innovation can affect each other and it is difficult to realize the enterprises' sci-tech innovation without the financial support. Through using a lot of data, Dabla-Norris etc (2010) ${ }^{[3]}$ verified that finance can make a difference to enterprise innovation activities within the country where the financial system is well-developed. Domestic scholars researched sci-tech finance and sci-tech innovation later than foreigners. Zhao Changwen etc(2009) ${ }^{[4]}$ firstly defined the concept of "science and technology finance(for sci-tech finance)" . Soon afterwards, the domestic scholars mainly focused on the micro and macro level of sci-tech finance. Zheng Jingyuan (2009) ${ }^{[5]}$ believed that the development of high-tech industries needs 
financial support. Based on Synergetics, He ruiya and Zhang Yuxi (2014) ${ }^{[6]}$ evaluated the coupling coordination degree of 28 provincial regions in China by means of constructing public financial and sci-tech innovation coupling degree evaluation model. The results showed that China's provincial regional sci-tech innovation and public finance coordination is overall low. Most of the regional public finance lags behind sic-tech innovation.

Although domestic and foreign scholars have studied sci-tech finance and sci-tech innovation from different perspectives, there are still shortcomings, mainly as follows: (1) When many scholars studied on sci-tech finance, they did not pay more attention to the influence of sci-tech finance on sci-tech innovation, while, in fact, sci-tech finance will have direct or indirect influence on the Sci-tech innovation. (2) Most of the existing literatures evaluated sci-tech finance and sci-tech innovation by a single indicator. (3) At present, most researches ignored the threshold effect of the impact of sci-tech finance on sci-tech innovation, while, in fact, the impact of sci-tech finance on sci-tech innovation existed threshold effect.

In view of the above shortcomings, the contribution of this paper is: (1) It studies the impact of sci-tech finance on sci-tech innovation by using theoretical and empirical analysis methods. (2) It constructs a multi index evaluation system to evaluate the impact of sci-tech finance on sci-tech innovation. (3)To testify whether sci-tech finance can improve sci-tech innovation, and whether there is a threshold effect on the impact of sci-tech finance on sci-tech innovation, this paper selects the panel threshold model and uses the provincial panel data of the 29 provinces over $2001-2013$ period in China to analysis.

\section{Methodology}

The Panel Threshold Model. Based on the theoretical analysis, there may be nonlinear relationship between sci-tech finance and sci-tech innovation. Based on the panel threshold regression model (Hansen ,1999) ${ }^{[7]}$, this paper builds a panel regression model of sci-tech finance and sci-tech innovation. The model is set as follows:

$$
y_{i t}=u_{i}+x_{i t} \beta_{1} \cdot I\left(q_{i t} \leq \gamma\right)+x_{i t} \beta_{2} \cdot I\left(q_{i t}>\gamma\right)+\boldsymbol{\omega}_{i t} \mathbf{X}_{\mathrm{it}}+\varepsilon_{i t}
$$

In the model (1), $i=1,2, \ldots, N$ represent different regions, and $t=1,2, \ldots, T$ represent different years; $y_{i t}$ is explained variable and represents sci-tech innovation (innov_tech); $x_{i t}$ is explaining variables and represents sci-tech finance (fina_tech); $\mathbf{X}_{\mathbf{i t}}$ represent control variables, in order to eliminate the influence of other factors on sci-tech innovation, it controls the follow factors: economic development $(R G D P)$, industrial structure(stru_indu),financial deepening (deep_fina), human resource (human) and industrial agglomeration (sli); I(.) is an index function, the value is 1 only if the corresponding condition is established, otherwise the value is $0 ; \beta_{1}$ and $\beta_{2}$ are the parameters to be estimated in processing the first and second sci-tech finance threshold, $q_{i t}$ are parameters to be estimated and $\gamma$ is a specific threshold value; $u_{i}$ represents the individual effect, $\varepsilon_{i t}$ is a random disturbance term, and $\varepsilon_{i t} \sim i d d\left(0, \theta^{2}\right)$.

In parameter estimation, in order to eliminate the influence of individual effect $\left(\mu_{i t}\right)$, we use the variable observation value minus the average of the group and obtain this model:

$$
y_{i t}^{*}=x_{i t}^{*} \beta_{1} \cdot I\left(q_{i t} \leq \gamma\right)+x_{i t}^{*} \beta_{2} \cdot I\left(q_{i t}>\gamma\right)+\boldsymbol{\omega}_{i t} \mathbf{X}_{i t}^{*}+\varepsilon_{i t}
$$

Further, all individual observations are overlapped, and the model is obtained:

$$
\mathbf{Y}^{*}=\mathbf{X}^{*}(\gamma) \beta+\boldsymbol{\varepsilon}^{*}
$$

According to Hansen (1999), we first give an arbitrary threshold value, and use the least squares (OLS) to estimate the estimated value $\hat{\beta}(\gamma)$ of parameter $\beta$ :

$$
\hat{\beta}(\gamma)=\left[\mathbf{X}^{*}(\gamma)^{\prime} \mathbf{X}^{*}(\gamma)^{\prime}\right]^{-1} \mathbf{X}^{*}(\gamma)^{\prime} \mathbf{Y}^{*}
$$

The corresponding residual sum of square $S_{1}(\gamma)$ is as follows:

$$
S_{1}(\gamma)=\hat{\mathbf{e}}^{*}(\gamma)^{\prime} \hat{\mathbf{e}}^{*}(\gamma)
$$


Among them, $\hat{\mathbf{e}}^{*}(\gamma)=\mathbf{Y}^{*}-\mathbf{X}^{*}(\gamma) \beta^{*}(\gamma)$. By minimizing the corresponding $S_{1}(\gamma)$ in model (5), we obtain the estimated value of $\gamma$.

$$
\hat{\gamma}=\arg \min S_{1}(\gamma)
$$

According to model (6), we can obtain that $\hat{\beta}=\hat{\beta}(\hat{\gamma})$, residual vector $\hat{\mathbf{e}}^{*}=\hat{\mathbf{e}}^{*}(\hat{\gamma})$ and residual variance $\hat{\theta}^{2}(\hat{\gamma})$.

After the parameter values obtained from the previous models, we need to test whether there is a threshold effect and whether the threshold value is a true value. In test for the presence of a threshold effect, the original hypothesis $\mathrm{H}_{0}$ is $\beta_{1}=\beta_{2}$ and the alternative hypothesis $\mathrm{H}_{1}$ is $\beta_{1} \neq \beta_{2}$, test $F_{1}$ statistic and $F_{1}=\left(S_{0}-S_{1}(\hat{\gamma})\right) / \hat{\theta}^{2}(\hat{\gamma})$. This paper uses "Bootstrap" proposed by Hansen $(1999)^{[7]}$ to simulate the asymptotic distribution of likelihood ratio test, and then obtain the $\mathrm{P}$ value of the asymptotic distribution. If the $\mathrm{P}$ value is less than the critical value, accept the alternative hypothesis, and this means there is a threshold effect. For the test of whether the threshold value is equal to the true value, this paper uses Hansen (1999) ${ }^{[7]}$ approach and defines: $L R(\gamma)=\left(S_{1}(\gamma)-S_{1}(\hat{\gamma})\right) / \hat{\theta}^{2}(\hat{\gamma})$. If $L R(\gamma) \leq-2 \ln (1-\sqrt{1-a})$ in a given significance level $a$, we accept the original hypothesis.

Through the parameters estimation and complete a single threshold test, if there is a multiple threshold effect, we need test second or more threshold values until the original hypothesis cannot be rejected. Due to the principle of the multiple threshold test is similar to the single threshold test, and it is unnecessary to go into more details.

\section{Variables and Data Description}

Sci-tech Innovation (inno_fina). This paper is based on the idea of Xu Yulian (2011) ${ }^{[8]}$, Song Yuegang and Du Jiang (2015) ${ }^{[9]}$, evaluates sci-tech innovation mainly in the four aspects, such as Table1.

Table 1 Evaluation System and Weight of Sci-tech Innovation

\begin{tabular}{c|l|c}
\hline Variable & \multicolumn{1}{|c}{ Evaluating Indicator } & Weight \\
\hline Input & R\&D full time equivalent & 0.056 \\
(in_tech) & R\&D internal expenditure /GDP & 0.042 \\
& Total funding for R \& D institutions & 0.105 \\
\hline \multirow{2}{*}{ Output } & Number of patent applications accepted & 0.119 \\
(out_tech) & Number of scientific papers indexed & 0.075 \\
& New product sale revenue /main business income & 0.136 \\
\hline Diffusion & Acontract amount of technical market & 0.147 \\
(diff_tech) & Amount of foreign technical contract introduced by region & 0.136 \\
\hline \multirow{2}{*}{ Environment } & Number of high-tech company & 0.080 \\
(envi_tech) & Students in Colleges per million people & 0.027 \\
& Per capita GDP & 0.040 \\
& Per capita ducational expenditure & 0.037 \\
\hline
\end{tabular}

Sci-tech Finance (fina_tech). The research of sci-tech finance is less on the domestic and foreign literatures, and there is no unified standard indicator on the evaluation of sci-tech finance. This paper evaluates in six aspects based on the idea of Xu Yulian (2011) ${ }^{[8]}$, such as Table 2. 
Table2 Evaluation System and Weight of Sci-tech Finance

\begin{tabular}{c|c|c}
\hline Evaluating Indicator & Unit & Weight \\
\hline Total credit of sci-tech & Billion RMB & 0.129 \\
Sci-tech credit/GDP ratio & Percentage & 0.072 \\
Listed sci-tech companies number & Per & 0.304 \\
Listed sci-tech companies value & Pillion RMB & 0.239 \\
Venture capital institutions & Per & 0.097 \\
Venture capital investment & Pillion RMB & 0.159 \\
\hline
\end{tabular}

Control Variables. In fact, sci-tech innovation depends not only on the support of sci-tech finance, but also other factors. This paper focuses on some possible influence factors to control. these specific factors are as follows:

(1) Economic development (RGDP). This paper uses the per capita GDP to measure the level of economic development.

(2) Industrial agglomeration(sli). This paper uses specialized index (SLI) to measure the degree of industrial agglomeration.

(3) Industrial structure (stru_indu). This paper selects the third industrial output value accounting for GDP ratio to measure the industrial structure.

(4) Human resource (human). This paper chooses the average length of schooling of the labor force to represent the investment of human resource.

(5) Financial deepen (deep_fina). This paper uses the total amount of credit accounting for GDP ratio measure the degree of financial deepen.

Data sources and their processing. In order to ensure the research objective and the data available, this paper selects provincial panel data over 2001-2013period in 29 provinces in China, except Tibet autonomous region and Hainan province. All the data are from the annual "China Statistical Yearbook", "China Financial Yearbook", CSMAR, WIND and EPS database.

\section{Econometric Results}

Threshold Effect Test. According to the previous ideas, we test whether there is a threshold effect between sci-tech finance and sci-tech innovation, in order to determine the number of thresholds and model forms. Table 3 gives F statistics among thresholds and P value the "Bootstrap" method. The results show that the single threshold and double threshold is remarkable in 1\% and 5\% level respectively, and $\mathrm{P}$ value is 0.010 and 0.017 , but the three threshold is not significant. It indicates that the influence of sci-tech finance on sci-tech innovation is non-linear. Table 4 gives the estimate and confidence interval of the double thresholds, and Figure 1 explains the formation process of the threshold estimate and confidence interval with the likelihood ratio function in different levels of economic development.

Table 3 Threshold Effect Test Results

\begin{tabular}{ccccccc}
\hline \multirow{2}{*}{ Variable } & \multirow{2}{*}{ F Statistics } & \multirow{2}{*}{ P Value } & \multirow{2}{*}{ BS } & \multicolumn{3}{c}{ Critical Value } \\
\cline { 5 - 7 } & & & & $1 \%$ & $5 \%$ & $10 \%$ \\
\hline Single threshold & $13.123^{* * *}$ & 0.010 & 1000 & 13.326 & 4.554 & 2.455 \\
Double threshold & $16.626^{* *}$ & 0.017 & 1000 & 27.084 & -1.195 & -2.124 \\
Three threshold & 1.993 & 0.146 & 1000 & 6.201 & 3.626 & 2.488 \\
\hline
\end{tabular}

Note:***,* and * indicate the significant level is $1 \%, 5 \%$ and $10 \%$ (the same below).

Table 4 Threshold Estimation Results

\begin{tabular}{ccc}
\hline & Threshold Estimate Value & Confidence Interval \\
\hline Threshold value $r_{1}$ & 5.090 & {$[3.374,5.786]$} \\
Threshold value $r_{2}$ & 9.124 & {$[8.051,9.124]$} \\
\hline
\end{tabular}



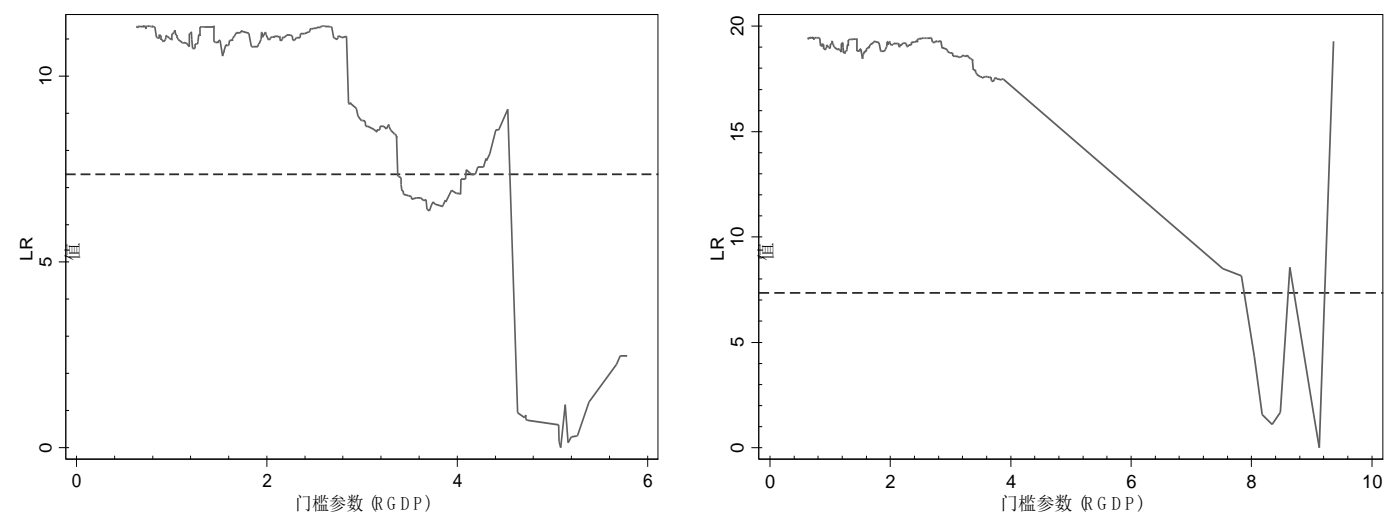

Figure 1 Threshold Estimation and Confidence Interval

Threshold Panel Regression Analysis. Table 5 lists the results of parameter estimation under the same variance and different variance, respectively. First, the results show that when the level of economic development for RGDP is lower than the first threshold value of 5.090, sci-tech finance coefficient is significantly negative. It suggests that sci-tech finance doesn't promote the sci-tech innovation in the low level of economic development, on the contrary, it has a negative impact on the sci-tech innovation. Second, when the economic development level is higher than the first threshold of 5.090, the coefficient of sci-tech finance is significantly positive, indicating sci-tech finance can promote sci-tech innovation. When the level of economic development is higher than the second threshold value of 9.124, the coefficient of sci-tech finance increases obviously, suggest that sci-tech finance can enhance sci-tech innovation mostly. Last, for the other control variables, human resources can promote sci-tech innovation significantly, while the coefficient of financial deepen is significantly negative, it inhibits sci-tech innovation, the impact of sli and industrial structure is not significant. In short, it is not a simple linear relationship between sci-tech finance and sci-tech innovation, and there is a threshold effect.

Table 5 Results of Threshold Model Parameters Estimation

\begin{tabular}{cccc}
\hline Variable & Coefficient & $\mathrm{T}(\mathrm{A})$ & $\mathrm{T}(\mathrm{B})$ \\
\hline fina_tech $(R G D P \leq 5.090)$ & -0.0414 & $-3.03^{* * *}$ & $-4.22^{* *}$ \\
fina_tech $(5.090<R G D P \leq 9.124)$ & 0.0434 & $4.07^{* * * *}$ & $2.96^{* * *}$ \\
fina_tech $(9.124<R G D P)$ & 0.138 & $4.30^{* * *}$ & $11.81^{* * * *}$ \\
$R G D P$ & 2.651 & $1.76^{*}$ & 1.26 \\
sli & 0.244 & 0.82 & 1.04 \\
stru_indu & -0.0156 & -0.12 & -0.09 \\
deep_fina & -0.735 & $-4.28^{* * *}$ & $-2.69^{* * *}$ \\
human & 0.623 & $2.56^{* *}$ & $1.93^{*}$ \\
cons & 25.00 & 1.40 & 0.62 \\
\hline
\end{tabular}

Note: A and B respectively represent T value of conventional standard error and robust estimation.

\section{Conclusion}

This paper uses the provincial panel data of 29 provinces (except Tibet and Hainan) in China from 2001 to 2013, to empirical analysis the threshold effect between sci-tech finance and sci-tech innovation. The conclusion is blow:

(1)The influence of sci-tech finance on sci-tech innovation in Chinese provinces (municipalities and autonomous regions) is not a simple linear relationship, and has threshold effect in the different levels of economic development.

(2)In the lower level of economic development, sci-tech finance has a negative impact on sci-tech innovation, but when the level of economic development to a certain extent, sci-tech can promote the upgrading of sci-tech innovation capacity.

Therefore, in order to promote sci-tech innovation, we should improve the local economic development level, develop sci-tech finance, and increase the financial support, to promote sci-tech innovation to enhance in China. 


\section{Reference}

[1]King R G, Levine R. Finance and growth: Schumpeter might be right[J]. The quarterly journal of economics, 1993: 717-737.

[2]Neff C. Corporate finance, innovation, and strategic competition[M]. Springer Science \& Business Media, 2012

[3]Dabla-Norris E, Kersting E, Verdier G. Firm productivity, innovation and financial development[M]. International Monetary Fund, 2010.

[4]Zhao Changwen, Chen Chunfa, Tang Yingkai. Science and technology finance [M]. Beijing: Science Press, 2009

[5]Zheng Jingyuan. Research on financial support for the development of high tech industry in China[J]. scientific management research, 2009,05:101-103

[6]He ruiya, Zhang Yuxi. Study on the coordination evaluation system of regional science and technology innovation and public financial system - Analysis based on 28 provinces in China[J].Scientific and technological progress and Countermeasures, 2014,07:31-37.

[7]Hansen B E. Threshold effects in non-dynamic panels: Estimation, testing, and inference[J]. Journal of econometrics, 1999, 93(2): 345-368

[8]Xu Yulian, Wang Yudong, Lin Yan. Evaluation on coupling coordination degree between regional science and sci-tech innovation and sci-tech finance[J]. science and technology management, 2011,12:116-122

[9]Song Yuegang, Du Jiang. Institutional change, OFDI reverse technology spillover and sci-tech innovation[J].world economic research, 2015,09:60-73+128.

[10]Townsend R M, Ueda K. Financial deepening, inequality, and growth: a model based quantitative evaluation[J]. The Review of Economic Studies, 2006, 73(1): 251-293. 